\title{
LA FIGURA DEL RESTABLECIMIENTO DEL DERECHO EN EL SISTEMA PENAL ACUSATORIO
}

The mechanism of rights restoration in the accusatory criminal system

Meliza Salcedo Alarcón ${ }^{1}$

Recibido: 12 de septiembre 2019 - Aceptado: 30 de noviembre de 2019

\section{RESUMEN}

El Restablecimiento del derecho es una figura jurídica contemplada en la ley procesal penal, consistente en proteger, en cualquier momento, los derechos de las víctimas en el proceso criminal. Esta institución viene a tomar importancia, específicamente, cuando se tiene certeza de la existencia de un hecho antijurídico que dio como resultado un daño antijurídico, con independencia de la búsqueda del sujeto activo de la conducta generadora del daño.

Como consecuencia de esa relevancia procesal, se ofrece, en este artículo de reflexión, la oportunidad, no solo, de entender la naturaleza y los fines de esta institución jurídica, sino de aclarar aspectos tales como, la procedencia, competencia y el tipo de decisión que debe producirse en relación con el momento procesal en que se encuentren los actores y algunos detalles que todo litigante, fiscal e incluso juez, debe tener en cuenta a la hora de enfrentarse a un restablecimiento del derecho.

Palabras clave: Restablecimiento del derecho; Código de procedimiento criminal; Proceso criminal colombiano; derechos de las víctimas.

\begin{abstract}
The Restoration of rights is a legal figure identified in criminal procedure law, consisting of protecting, at any time, the rights of victims in the criminal process. This institution comes to take importance, specifically, when there is certainty of the existence of an unlawful act that resulted in unlawful damage, regardless of the search for the active subject of the behavior that generated the damage.

\footnotetext{
1 Abogada de la Universidad de San Buenaventura, especialista en Ciencias Penales y Criminológicas de la Universidad de Cartagena y en Derecho Procesal de la Universidad Libre de Colombia. Actualmente litigante y asesora externa empresarial en Derecho Penal y Constitucional. ORCID: https://orcid.org/0000-0003-1573-4595 Mail: meliza.sa1992@ gmail.com
} 
As a consequence of that procedural relevance, this reflection paper offers the opportunity, not only, to understand the nature and purposes of this legal institution, but to clarify aspects such as, the origin, competence and the type of decision that must occur in relation to the procedural moment in which the actors are and some details that every litigant, prosecutor and even judge, must take into account when facing rights restoration procedures.

Keywords: Rights restoration; Criminal Procedure Code; Colombian criminal process; victims' rights.

\section{Generalidades}

Es común escuchar de estudiantes de derecho, litigantes o de abogados en general que el restablecimiento del derecho hace referencia a la indemnización de perjuicios, que es igual a resarcir o en algunos casos un poco más acertados, atinan a decir que corresponde a la acción de cancelar inscripciones, pero generalmente no consiguen definir en qué consiste esta figura jurídica.

En cuanto al concepto genérico de la palabra Restablecer, pues bien, el término según la Real Academia Esrpañola significa:

Restablecer (se). Como transitivo, 'volver a establecer [algo]'y, como intransitivo pronominal, 'recuperarse de un daño o una enfermedad'.

A diferencia de Resarcir, que según la misma fuente es:

Resarcir. Tr. Indemnizar, reparar, compensar un daño, perjuicio o agravio. U.t. c. prnl.

Entonces bien, al comparar los conceptos, no es necesario hacer mayores esfuerzos mentales para entender su diferencia, no obstante, no pasa lo mismo cuando se aplican los conceptos en el Derecho Penal, pues la norma no establece un contraste expreso entre las dos nociones, es aquí donde es indispensable analizar en contexto el concepto, lo cual implica si quiera un breve pasaje por la doctrina.

Según Barbosa (2007, Pág. 115) “el restablecimiento del derecho supone devolver las cosas al estadio previo a la afectación de un derecho o impedir que los efectos nocivos del delito se produzcan o se incrementen". Hasta ahí no hay novedad en su concepto, sin embargo, continúa diciendo que, no es lo mismo que indemnizar, ya que esto sería limitar su espectro, pues afirma que restablecer corresponde a una acepción más amplia, cuando se trata brindar una compensación del derecho que en principio se afectó y una de esas formas puede ser el factor pecuniario o indemnización, pero este no es el único modo. 
Meliza Salcedo Alarcón

Se comparte la definición de Barbosa, aunque pareciera que la misma se queda corta en cuanto a las demás formas y no pareciera ahondar en el solo hecho de poder volver las cosas al estado en que se encontraban, antes de la comisión de la conducta punible-.

Por otro lado, el doctor Gilberto Martínez (2006, Pág. 25), al hablar del Restablecimiento del derecho como principio rector y garantía procesal, manifiesta textualmente que "Es, por tanto, obligación del funcionario judicial hacer los esfuerzos necesarios para lograr el restablecimiento del derecho, que lógicamente incluye la indemnización de perjuicios" (subrayado nuestro).

En el mismo sentido los planteamientos del profesor Vicente Gaviria (2002, Pág.217), quien en contradicción a los esbozos de Tamayo Jaramillo (1993, Pág. 83) afirma que "La indemnización de perjuicios constituye una forma de restablecimiento del derecho, pues con ella se busca dejar al perjudicado indemne, esto es, en la misma situación en que se encontraba antes de cometerse el delito".

Yerran los autores al afirmar que, por lógica, el restablecimiento del derecho incluye una indemnización de perjuicios. Primero porque al hablar de indemnización, se hace referencia a un pago pecuniario, y ese pago debe hacerlo quien el juez obligue en una sentencia condenatoria, en el código de procedimiento penal colombiano (ley 906 de 2004), esta indemnización de perjuicios se solicita después de ejecutoriada la sentencia condenatoria, y lleva por nombre incidente de reparación integral. En este momento procesal que haya quedado ejecutoriada la sentencia, ya se tiene certeza de quien es el responsable de la conducta punible, entonces sí sería lógico que él indemnice a las víctimas.

Pero el restablecimiento del derecho tiene una característica de intemporalidad, aspecto que se abordará con posterioridad y con mayor detenimiento, por ahora se dirá que puede solicitarse en cualquier momento procesal, eso quiere decir que incluso sin tener a una persona acusada o imputada, puede ser pedido. Aspecto que difiere totalmente de las garantías constitucionales de los procesados en caso de obligar a pagar perjuicios, pues como si aún no se tiene certeza de responsabilidad, como se puede obligar a indemnizar con el patrimonio de quien aún se considera inocente.

Diferente a ello es restablecer el derecho, pues cuando existe certeza de que la comisión de determinada conducta punible ocasionó un daño, aun sin saber quién fue el responsable de la comisión, se puede restablecer, es impersonal, no se trata de decir - usted señor procesado restablezca el derecho-. No, es una facultad del funcionario judicial.

Atinado el concepto de Bernal y Montealegre (2004, Pág. 350), quienes manifiestan que esta figura en estudio se tiene como una idea más compleja que la indemnización, ya que 
supone la posibilidad de garantizar el goce del derecho afectado por la comisión del hecho punible, por un lado, cuando el juez adopte medidas que permitan que los perjudicados puedan continuar con el disfrute de su derecho en caso que este hubiese sido interrumpido, o, de ser posible, volver la situación o condición preexistente a la comisión del hecho, en caso que la consecuencia de este haya impedido la supresión del derecho. De lo contrario, solo se debe proceder con la reparación.

De acuerdo se está, con la complejidad dada por los doctores a esta figura, con relación a la indemnización, ya que es muy fácil tazar perjuicios y exigir pagarlos, pero se ve la complicación cuando de devolver las cosas al estado anterior del daño, se trata.

En esta noción, los letrados abarcan de manera general la posibilidad y advierten que, en caso de no existir, habrá lugar a la reparación integral. Razón por la cual se adopta esta definición para efectos de entender de manera precisa que es el restablecimiento del derecho en el marco de este estudio.

\section{Derechos susceptibles de restablecimiento}

Abordar el tema de los derechos susceptibles de restablecimiento y crear una lista con ellos sería un desgaste argumentativo, pues basta con analizar en cada caso en concreto si hay posibilidad de restablecer o no el Derecho o una parte de él, conforme al concepto que se adoptó anteriormente.

Sin embargo, algunos artículos de la ley 906 (2004), desarrollados por la jurisprudencia, permiten abordar una serie de casos en los que comúnmente se restablecen derechos, y ese sería el tema que nos ocupe en este capítulo. Pero antes de abordarlo, va a ser de gran importancia retomar el tema de las medidas necesarias que se plantean en el decreto 2700 , y es para decir que, no sólo en los ejemplos que con posteridad se pondrán de presente, se puede restablecer derecho, pues en los casos en los que quizá no se pueda volver de facto las cosas al estado anterior de la vulneración del derecho, de pronto si puede existir la posibilidad de hacer cesar alguna contingencia y que el funcionario judicial adopte medidas que permitan a las víctimas continuar con el disfrute del derecho, en el estado en que se encuentre, o que si quiera esas medidas sirvan para restablecer en parte las situaciones que impiden el goce del mismo.

Sea cual sea el caso, las medidas necesarias serán invocadas en vía a volver las cosas al estado anterior de la comisión del delito, "restitutio in pristinum" y esa premisa implica que el funcionario judicial resuelva asuntos extrapenales, que, de alguna manera, fueron el origen de un daño antijurídico. 
Meliza Salcedo Alarcón

Siguiendo con el mismo ejemplo anteriormente mencionado; si en ese homicidio, el occiso, el día de los hechos, llevaba en su bolsa una joya costosa de su padre, sería absurdo pretender revivir a la víctima mortal, pero lo que sí es posible, es intentar restablecer así sea en una parte el derecho, pues con tomar las medidas necesarias para que la joya vuelva a manos del padre, se estaría restableciendo una parte del daño, por lo menos, en cuanto a lo patrimonial, y además del dolor por la pérdida de un ser, no se ve afectada la víctima con soportar la carga monetaria por la joya.

La estructura conceptual de las medidas necesarias está dada porque si no se toman esas medidas necesarias, se estaría poniendo en riesgo un derecho, en este caso, más bien, seguiría latente la vulneración de los derechos de la víctima o de cualquier tercero interesado. Sin embargo, la jurisprudencia SU 182 (1998) de la Corte Constitucional ha dicho que esas medidas no pueden conllevar a que la víctima o el interesado goce de un derecho mejor del que disfrutaba, es decir que la decisión en cualquier caso debe ser proporcional a la vulneración del derecho.

Ahora bien, retomando la mención de los casos en los que comúnmente se restablecen derechos, es preciso citar los siguientes artículos de la ley 906 (2004): Artículo 85: Suspensión Del Poder Dispositivo; Artículo 91: Suspensión y Cancelación de La Personería Jurídica; Artículo 97: Prohibición de Enajenar; Artículo 99: Medidas Patrimoniales a favor de Las Víctimas; Artículo 101: Suspensión y Cancelación de registros obtenidos fraudulentamente.

Dentro de esos artículos antes mencionados, en algunos se específica la competencia exclusiva del fiscal para restablecer derechos, también se mencionan los casos cuando el fiscal deberá solicitarlo ante los jueces de control de garantías. De aquí a que en algunas ocasiones ya la competencia viene dada y no es necesario hacer los análisis exhaustivos para determinarla.

Frente a estos restablecimientos expresados tácitamente en la ley, la jurisprudencia constitucional ha desarrollado algunos, como es el caso de la cancelación y suspensión de registros obtenidos fraudulentamente (artículo 101 del código de procedimiento Penal Colombiano (Ley 906, 2004). Con respecto a esto, la Corte Constitucional en la sentencia C-060 (2008) estableció un precedente judicial en torno a todo lo que giraba en esta medida, determinando necesidad, competencia, intemporalidad, factores característicos ${ }^{2}$ y demás aspectos fundamentales, que brevemente se estudiaran.

\footnotetext{
2 Existen otros artículos de restablecimiento del derecho en el código de procedimiento penal (2004) sin embargo solo se analizó el del artículo 101, por el gran despliegue jurisprudencial que hizo la Corte Constitucional en la sentencia C- 060 de 2008. Pues basados en estos postulados se generalizó en los demás casos con respecto a la intemporalidad del Restablecimiento del derecho y la competencia del mismo, de ahí su importancia en este estudio.
} 


\section{Análisis de la Sentencia C-060 de 2008 de la corte constitucional colombiana.} Específicamente en la sentencia mencionada C-060 (2008) se busca determinar si la regulación contenida en el artículo 101 de la Ley 906 (2004), y especialmente en la expresión "en la sentencia condenatoria", permite el adecuado ejercicio de los derechos a quienes fueron víctimas de la conducta punible que se investiga.

Para ello es necesario realizar un estudio sistemático de las anteriores normas procesales, tales como el artículo 61 del decreto 2700 (1991), 66 de la ley 600 (2000) y el 101 de la ley 906 (2004) y tras una comparación de estas tres normas, se evidencia que tienen en común la exigencia de que se haya acreditado la tipicidad del delito de que se trata, requerimiento que resulta lógico en la medida en que de esta manera la administración de justicia actúa sobre bases firmes, sin alterar, antes de contar con muy sólido sustento, los derechos de terceros de buena fe a cuyo nombre pudiere encontrarse el título que es objeto de cancelación.

En efecto, que previamente tenga que acreditarse la cabal demostración de la tipicidad elementos objetivos del tipo -, preserva la presunción de buena fe hasta el momento en que quede plenamente desvirtuada, o que se imponga el derecho genuino por encima de los que se edificaron sobre bases espurias.

Posiblemente en esta misma línea, la norma más recientemente expedida agregó al "convencimiento más allá de toda duda razonable" la circunstancia de que esta decisión sólo podría adoptarse "en la sentencia condenatoria".

Pero este cambio normativo implica un inconstitucional retroceso en la protección de los auténticos titulares del derecho, que ha de ser restablecido por mandato de un principio rector del art. 22 del Código de Procedimiento Penal (Ley 906, 2004), el cual debe prevalecer y aplicarse obligatoriamente sobre cualquier otra disposición de tal Código (art. 26 ib.), "para hacer cesar los efectos producidos por el delito" y procurar que "las cosas vuelvan al estado anterior" a la perpetración criminosa, de modo que, si ello fuere posible, todo quede como si no se hubiere atentado contra el respectivo bien jurídico, lo cual debe realizarse independientemente de la responsabilidad penal.

Ese valioso principio fundamental del restablecimiento del derecho, incluido como norma rectora de todos los estatutos procesales penales colombianos desde el Decreto 050 de 1987, adquirió expresa incorporación constitucional en 1991, en el texto original del artículo 250 (numeral $1^{\circ}$ ), con reafirmación a partir del Acto Legislativo 03 (2002) (numeral $6^{\circ}$ ), de manera que cualquier disposición legal que lo contraríe será inconstitucional. 
Meliza Salcedo Alarcón

Esa reforma cae también en la incongruencia. Las dos normas anteriores a la del fragmento demandado permitían (permiten, en las acciones penales que se continúan adelantando bajo el código de procedimiento penal Colombiano), adoptar esta decisión "en cualquier momento de la actuación" en que aparezca demostrada la tipicidad - los elementos objetivos - de la conducta punible, oportunidad que en el sistema procesal acusatorio no procedería, en contravía a lo que es su plausible avance en defensa de los derechos de las víctimas.

Adviértase que, tal como lo exponen varios intervinientes, pueden existir diversas situaciones en las que se cuente a cabalidad con prueba suficiente sobre los elementos objetivos del tipo penal, sin que se reúnan, en cambio, las exigentes condiciones que son necesarias, particularmente en cuanto a la responsabilidad penal, para poder proferir sentencia condenatoria, dispuesto en el art. $7^{\circ}$ de la Ley 906 (2004), siendo necesario entonces emitir un fallo absolutorio.

También pueden presentarse casos en los que exista "convencimiento más allá de toda duda razonable" sobre el carácter apócrifo del título de adquisición, pero ninguna información acerca de los posibles responsables de dicha adulteración, circunstancia en la cual no podrá procederse al archivo de las diligencias por parte de la Fiscalía, por cuanto esta situación no encuadra en los supuestos que para esta decisión prevé el artículo 79 de la misma Ley 906 (2004). Por el contrario, el ente investigador debe continuar ejerciendo la acción penal a fin de poder determinar quiénes fueron los autores de dicha conducta punible, y mientras tanto, de acuerdo con lo establecido en los ya citados artículos 22 ibídem y 250.6 de la Constitución Política de Colombia (1991), deberá adoptar las medidas necesarias para hacer cesar los efectos producidos por el delito, y de ser posible, que las cosas vuelvan al estado anterior, independientemente de la responsabilidad penal.

Finalmente, puede surgir también un factor de extinción de la acción penal, como alguna causal de preclusión u otras situaciones que la terminan (muerte del procesado antes de proferirse sentencia, prescripción o, en los casos previstos por la ley, mutatis mutandis y dentro de sus propias condiciones legales y aún constitucionales, algunas de ellas preservantes de los derechos de las víctimas, como indemnización integral, pago, desistimiento, amnistía propia, aplicación del principio de oportunidad).

Así las cosas, no obstante que se hubiere arribado al "convencimiento más allá de toda duda razonable" sobre el carácter fraudulento del título en cuestión, la ocurrencia de cualquiera de las situaciones últimamente reseñadas traería como consecuencia la definitiva imposibilidad, pues no habrá fallo condenatorio, de obtener la cancelación del título apócrifo, necesaria para lograr el pleno restablecimiento del derecho de la víctima. 
En la misma línea planteada por el demandante, la Corte encuentra que esta situación se deriva precisamente de que la norma demandada exija que dicha decisión se tome exclusivamente en la sentencia condenatoria, que nunca se producirá en las comentadas eventualidades. De no existir tal restricción, la cancelación podría ordenarse siempre que objetivamente exista prueba suficiente de la contrafacción, de manera semejante a como ocurriera con la aplicación de las normas anteriores, transcritas páginas atrás.

Es claro entonces que por efecto del requisito contenido en la expresión "En la sentencia condenatoria”, el segundo inciso del artículo 101 parcialmente demandado puede dar lugar a situaciones en las que antijurídicamente se pierda por completo la posibilidad de que la víctima obtenga el pleno restablecimiento de su derecho, mediante la cancelación de los títulos y registros fraudulentamente obtenidos.

Al analizar medidas semejantes a ésta y teniendo en cuenta los alcances de la protección constitucional "a la propiedad privada y los demás derechos adquiridos con arreglo a las leyes civiles" (art. 58), la Corte ha resaltado, tal como ahora reitera, la importancia de que los correctivos previstos en la ley para volver las cosas a su estado original y desvirtuar los derechos arrogados contrariando el orden jurídico, se apliquen de manera pronta y efectiva, de modo que se evite la continuación y/o la consumación de situaciones irregulares, así como la de los perjuicios que ellas injustamente causan.

Esta consideración, junto a la relativa a la importancia y especial protección constitucional que, según se ha explicado, tienen los derechos de los damnificados por los delitos, hacen que no resulte necesario, razonable ni justo que el restablecimiento se condicione de manera indefinida, o peor aún, pueda frustrarse definitivamente.

Por todo lo anterior, encuentra la Corte que, por efecto de la expresión demandada, algunas de las víctimas de este tipo de delitos no tienen completamente garantizado el derecho a acceder a la administración de justicia, para que pronta y cumplidamente se le defina la restitución a que tiene derecho, situación que a su turno vulnera, parcialmente, las garantías constitucionales del debido proceso y el restablecimiento del derecho (arts. 229, 29 y 2506 constitucionales, respectivamente).

Ha de resaltarse, claro está, que como constante frente a todo lo analizado, también opera el respeto debido a los principios fundamentales que trazan la forma, caracteres y fines del Estado social de derecho (arts. $1^{\circ}, 2^{\circ}$ y preámbulo de la Constitución).

Igualmente asiste razón a los argumentos atinentes a que, con la expresión demandada se impide que la Fiscalía General de la Nación cumpla a plenitud algunas de las obligaciones 
Meliza Salcedo Alarcón

que la Constitución le asigna, en relación con la protección y restablecimiento de los derechos e intereses de las víctimas, particularmente las listadas en los numerales $6^{\circ}$ y $7^{\circ}$ del actual texto del artículo 250 superior.

En efecto, dado que la cancelación de títulos de propiedad y registros fraudulentamente obtenidos es una medida eficaz y apropiada para lograr el restablecimiento del derecho y la reparación integral de las víctimas en un proceso penal, además dentro de los cánones de la justicia restaurativa, la Fiscalía debe, en ejercicio de las facultades antes indicadas, solicitar al juez la aplicación de esta medida, siempre que exista certeza suficiente sobre el carácter apócrifo de aquéllos. Así, resulta inconstitucional que tal medida sólo pueda adoptarse en caso de proferirse una condena, puesto que ello provoca la improcedencia de dicha solicitud cuando quiera que el proceso concluya con un pronunciamiento distinto a aquélla.

Se desprende de lo analizado que si bien resulta razonable que sólo al final del proceso se adopte una decisión definitiva sobre la cancelación de los títulos apócrifos, el hecho de que ello sólo pueda ocurrir dentro de la sentencia condenatoria, tal como lo exige el inciso $2^{\circ}$ del artículo 101 de la Ley 906 (2004), puede sin duda llegar a excluir el acceso de las víctimas a la administración de justicia, pues al terminar el proceso penal de diferente manera, quedaría extinguido para ellas y concretamente para el legítimo titular, el poder dispositivo sobre los bienes a que tales títulos se refieren. Se quebranta así la garantía de acudir a un debido proceso que la Constitución Política reconoce y se crea un obstáculo para el cumplimiento de algunas de las obligaciones que el texto superior le impone a la Fiscalía General de la Nación para que vele eficientemente, como le es indefectible hacerlo, por los intereses de las víctimas y contribuya a proteger y restablecer sus derechos.

Por lo anterior, concluye la Corte que la palabra "condenatoria" resulta entonces contraria al contenido de varias normas constitucionales, como los artículos 29 (debido proceso), 229 (acceso a la administración de justicia) y 250 (funciones de la Fiscalía General de la Nación).

En lo que atañe a la expresión "En la sentencia", que también hace parte del segmento normativo acusado, la Corte acoge parcialmente el planteamiento del demandante y los coadyuvantes, así como el de los impugnadores. Ello por cuanto, si bien se entiende que sólo al término del proceso penal puede existir certeza suficiente para justificar la definitiva cancelación de los títulos fraudulentamente obtenidos, no es menos cierto que dicha certeza bien puede haberse generado como resultado del debate probatorio surtido durante el proceso, aun cuando éste haya concluido, bien mediante sentencia absolutoria, bien por efecto de alguna otra decisión de las que supone la imposibilidad de continuarlo, como 
aquellas que implican la extinción de la acción penal, y todas las demás a que se tuvo oportunidad de referirse páginas atrás.

En desarrollo del principio de conservación del derecho, ello conduce entonces a la declaratoria de exequibilidad condicionada de la expresión "En la sentencia", bajo el entendido de que igualmente procederá la orden de cancelación definitiva de los títulos apócrifos cuando quiera que se dicte otra providencia que ponga fin al proceso penal.

En todo caso y para plena claridad, la Corte Constitucional advierte que en cualquier evento en que, de acuerdo con lo expuesto, la cancelación de los títulos apócrifos deba ordenarse en un contexto diferente al de la sentencia de fondo, dicha decisión sólo podrá tomarse en la medida en que, habiéndose permitido el pleno ejercicio del derecho de defensa y contradicción de quienes resultaren afectados por la cancelación, su derecho haya sido legalmente desvirtuado, lo que ocurre precisamente al alcanzarse el "convencimiento más allá de toda duda razonable" sobre el carácter fraudulento de dichos títulos, requisito cuyo rigor obviamente se mantiene, así no se logre la identificación, vinculación y condena de la o las personas penalmente responsables.

De acuerdo con lo que se ha dejado claro, en palabras de la Corte Constitucional, estas reglas y sub-reglas se aplicarán a los casos en que las discusiones versen sobre los mismos aspectos. No hay duda entonces que la cancelación, por ser definitiva se hará en cualquier decisión que ponga fin al proceso, mientras que la suspensión, por ser transitoria se adoptará en cualquier otra decisión. Finalmente, como complemento de lo expuesto, en los casos que no están plasmados en la ley, sino en los cuales se probará la creatividad (de los jueces al decidir y por supuesto de la fiscalía y las víctimas al momento de solicitar) de los involucrados para crear las medidas necesarias para restablecer los derechos en esos casos. Pues reiterando lo dicho, no todos los casos están textualmente en la ley, y a diario se encuentra en los juzgados solicitudes de Restablecimientos de Derechos no fundamentados en ningún artículo de la ley, simplemente se ingenian la manera de proteger los derechos de las víctimas de cualquier forma, lo cual es totalmente válido dentro de un Estado garantista de proteger los derechos fundamentales de sus asociados.

\section{Formas de restablecer el derecho en el proceso penal}

El restablecimiento del derecho podrá hacerse de manera de transitoria y de manera definitiva, eso dependerá de la etapa procesal en que se ubique la solicitud, lo cual va de la mano con la competencia de los jueces.

El proceso penal inicia con la querella, denuncia o de oficio. Posteriormente se realiza el acto de comunicación, de la indagación, a los presuntos responsables llamado formulación 
Meliza Salcedo Alarcón

de imputación y estos momentos, hasta la asignación del escrito de acusación, el proceso aún no tiene juez de conocimiento. Lo que implica que todas las audiencias que se realicen en ese interregno serán dirigidas por un juez de control de garantías, y se llamarán audiencias preliminares-.

Por otro lado, el restablecimiento del derecho, como ya se había mencionado, es intemporal, es decir, puede solicitarse en cualquier momento.

De acuerdo con esto, si el restablecimiento del derecho se solicita en cualquier momento de la indagación, antes de la formulación de acusación, la competencia será de los jueces de control de garantías y será una más de las audiencias preliminares que surgen en el proceso penal, será nominada porque, por su naturaleza, siempre se llamará -audiencia de solicitud de restablecimiento del derecho-.

Ahora bien, llegado la carpeta del proceso, a la asignación de juez de conocimiento, será éste el director de la investigación, quien dirige toda la actuación, por lo tanto, el mismo gozará de la competencia de ahí en adelante para todas las audiencias que surjan, pero la ley es clara en sus artículos, al mencionar que "el fiscal solicitará al juez de control de garantías..." por lo que es importante entonces detenerse para aclarar el sentido en el cual puede decidir cada juez en concordancia con su competencia.

Recordemos la sentencia C-060 (2008), la cual surge como consecuencia de una demanda de inconstitucionalidad de la expresión "en la sentencia condenatoria" del inciso dos, del artículo 101 de la ley 906 (2004). Pues en los eventos en que los procesos no culminaran con una sentencia condenatoria no habría lugar al restablecimiento del derecho, sin prever que puede terminar una investigación, con la preclusión, principio de oportunidad, entre otros casos, que no garantizan una sentencia condenatoria y que por ende no se daría el restablecimiento del derecho.

La Corte en esta decisión, se extiende explicando que el juez de control de garantías podrá suspender los títulos apócrifos, tal como lo dice el inciso primero del artículo citado, mientras que los jueces de conocimiento podrán cancelarlos de manera definitiva en cualquier decisión que ponga fin al proceso.

Sin embargo, es de resaltar, en virtud de esta misma decisión que, en los casos en que los jueces de control de garantías emitan decisiones que pongan fin al proceso, también se podrá dar la cancelación de los mencionados títulos, pues se cumpliría lo que dice la Corte, "se cancelarán en cualquier decisión que ponga fin al proceso". 
Teniendo como base la existencia de estipulaciones de esta magnitud, no queda ninguna duda que, para los casos de restablecimiento del derecho transitorios y definitivos, los cuales serán identificados uno por uno más adelante, se deberá adoptar esta misma subregla en cada uno de ellos, que, si bien la ley no lo ha plasmado en estas mismas palabras, si ha propiciado la diferenciación entre unos y otros.

En las formas temporales, taxativamente plasmadas en la ley se encuentran, la suspensión del poder dispositivo, suspensión de la personería jurídica, prohibición de enajenar y suspensión de registros obtenidos fraudulentamente. No obstante, por parte de la fiscalía también se podrán restablecer derechos temporales o transitorios, de acuerdo a lo contemplado en el artículo 99 de la ley procesal penal, y es en teoría lo que corresponde al ejemplo que en un momento se planteó acerca de la devolución, a la víctima, de los objetos que hubieren sido recuperados, lo que sería un restablecimiento definitivo, pero el artículo también expresa en el Numeral 2 un restablecimiento provisional, relacionado con autorizar a la víctima el uso y disfrute provisional de bienes que, habiendo sido adquiridos de buena fe, hubieran sido objeto de delito.

Vale decir que, ante todos estos casos, deberá estar dirigiendo la actuación el juez de control de garantías, cuando el proceso esté en la etapa indagatoria, y será él quien disponga restablecer los derechos de manera transitoria, siempre que sus decisiones no sean las que pongan fin al proceso. Pues de ser este este el caso si podrá restablecer derechos de forma definitiva. Esto de conformidad a los argumentos planteados por la Corte constitucional en la sentencia precitada C- 060 (2008) y la sentencia 40246 (2012) de la Corte Suprema de Justicia, Sala de Casación Penal, cuyas vicisitudes se abordarán más adelante.

Por su parte, dentro de las formas definitivas de restablecimiento del derecho se encuentran la cancelación de la personería jurídica y la de registros obtenidos fraudulentamente.

En estos casos tendrán competencia los jueces de conocimiento, quienes conocen los procesos en la etapa de la investigación y juzgamiento y serán los encargados, por regla general, de emitir decisiones que pongan fin al proceso, esto respetando la excepción del conocimiento de los jueces de control de garantías para preclusión o principio de oportunidad en los cuales no será competencia de los Juzgadores de conocimiento. Tema que, como ya se mencionó, será explicado con posterioridad.

\section{Vocación o legitimidad}

La norma ha estipulado textualmente en los artículos mencionados con anterioridad, que será el fiscal quien solicitará al juez, que decida sobre las medidas necesarias para el restablecimiento del derecho. Conforme esto con la norma rectora que en su artículo 250 
Meliza Salcedo Alarcón

expresa que la Fiscalía solicitará ante el juez las medidas necesarias para disponer sobre el Restablecimiento del derecho, adicionalmente en el artículo 22 del código de procedimiento penal, también se menciona a la Fiscalía y a los jueces para la toma de las medidas necesarias.

Pero en ninguna de estas estipulaciones, mencionan a la víctima como legitimada por activa para solicitar la medida de restablecimiento del derecho. No obstante, estas medidas pueden ser suscitadas por las víctimas directamente o por intermedio de la Fiscalía, al tenor de lo previsto en el artículo 134 de la Ley 906 (2004), según el cual las víctimas en garantía de su seguridad y el respeto a su intimidad podrán además de solicitar las medidas indispensables para su atención y protección.

En ese sentido la sentencia C-209 (2007) trae un despliegue jurisprudencial en cuanto al papel de la víctima en el marco del proceso penal, regulado por la ley 906 (2004), a raíz de esto declaró inexequibles las expresiones " $y$ contra esta determinación no cabe recurso alguno” del artículo 327 de la Ley 906 (2004) y “con fines únicos de información” del inciso final del artículo 337 de la misma ley. Así mismo, declaró la exequibilidad condicionada de una serie de normas con el objetivo de conceder algunas facultades a las víctimas dentro del proceso penal.

En esta sentencia, también se consideró que los derechos de las víctimas se encuentran protegidos en el sistema penal con tendencia acusatoria instaurado por la Ley 906 (2004), aunque el esquema de su intervención no deberá ser idéntico al consagrado en la Ley 600 (2000), sino que debe ser compatible con los rasgos estructurales y las características esenciales de este nuevo sistema procesal.

Fue así como la Corte Constitucional reconoció que la forma como puede actuar la víctima en el proceso penal de tendencia acusatoria implantado por el Acto Legislativo 03 (2002), depende de varios factores: (i) del papel asignado a otros participantes, en particular al Fiscal; (ii) del rol que le reconoce la propia Constitución a la víctima; (iii) del lugar donde ha previsto su participación; (iv) de las características de cada una de las etapas del proceso penal; y (v) del impacto que esa participación tenga tanto para los derechos de la víctima como para la estructura y formas propias del sistema penal acusatorio (2013).

A partir de esta sentencia se le da a la víctima la potestad para ejercer toda clase de solicitudes, pues por primera vez establecen cuáles serán las acciones que la víctima no podrá ejecutar en el desarrollo del proceso, por si misma, sino que podrá hacerlo por medio de la fiscalía, y estas limitantes versan sobre la preponderancia que tiene el equilibro de las partes en un sistema de esquema adversarial, como lo es, el instituido por la ley 906 (2004). 
Pero el restablecimiento del derecho no entra en esas excepciones, por lo cual es una garantía dada a las víctimas para poder solicitar el restablecimiento de sus derechos, cuando la fiscalía no lo haga.

De esta manera entonces la víctima, sea al juez de control de garantías, o al juez de conocimiento, depende de la etapa procesal en que se encuentre y si su solicitud será la de restablecer el derecho transitorio o definitivo, solicitará la realización de la audiencia de restablecimiento del derecho, y llegada el día y la hora para hacerlo, expondrá los hechos que fundamentan su petición, las razones de hecho y de derecho por las cuales se deberán restablecer los derechos, y la solicitud en especial, si su deseo es que se suspendan o se cancelen los supuestos de hecho que han ocasionado la vulneración de los derechos de las víctimas.

Con respecto a elevar claramente la solicitud, se debe decir que será fundamental, pues, si se diera el caso en que la víctima solicite al juez de control de garantías, el restablecimiento del derecho definitivo. Este deberá declararse incompetente para decidir sobre esa solicitud, y la razón es sencilla y es porque este juez sólo tiene competencia para restablecer el derecho transitoriamente, no definitiva. Y este sistema acusatorio, parte de una justicia rogada, por lo que los jueces deberán basar sus decisiones en el principio de congruencia, y deben resolver de acuerdo a lo que se les está solicitando. No puede suceder que el juez subsane el yerro de la solicitud y en su decisión aclare que como no puede restablecerlo definitivamente, lo hará transitoriamente. Pues eso no fue lo que le solicitaron por lo tanto deberá abstenerse.

De acuerdo a lo referenciado, la ley y la jurisprudencia ha sido clara en determinar quiénes serán los legitimados para invocar el restablecimiento del derecho, y según lo dicho serán los fiscales por estricta orden de la ley, y las víctimas por desarrollo jurisprudencial. Nada se dice a cerca de la posibilidad de que los jueces puedan solicitarla de oficio. Eso acabaría con la imparcialidad que debe tener el juzgador en relación a los derechos de las víctimas y de los terceros con interés dentro de los procesos en los cuales, a causa de un restablecimiento se vean afectados sus derechos patrimoniales, los cuales fueron obtenidos de buena fe.

Es por eso no se encuentra la posibilidad que de oficio el juez, independientemente del sentido de su decisión, sea capaz de afrontar un análisis que de entrada está siendo propuesto por él mismo y que requiere de la objetividad en su estudio para poder garantizar la imparcialidad en todos los ámbitos 
Meliza Salcedo Alarcón

\section{Juez competente según el criterio de la Corte Suprema de Justicia en el radicado 40246 de 28 de noviembre de 2012 .}

El tema que corresponde analizar en esta oportunidad se circunscribe a establecer cuál es el juez competente para conocer de una solicitud de restablecimiento del derecho con carácter provisional, esto es, si ello es del resorte del juez de control de garantías o lo es del juez de conocimiento.

El problema no se torna de fácil resolución cuando el artículo 114 de la Ley 906 (2004), al señalar las atribuciones de la Fiscalía General de la Nación para el cumplimiento de sus funciones constitucionales y legales, en su numeral 12, dispone que el restablecimiento del derecho se debe solicitar al Juez de conocimiento.

Más aún cuando se observa que esta disposición prácticamente reproduce el texto del numeral 6 del artículo 250 de la Constitución Política Colombiana (1991), modificado por el artículo 2 del Acto Legislativo 03 (2002), alusivo a las funciones deferidas al mismo ente.

De ahí que independientemente de que el artículo 153 de la Ley 906 (2004), refiera que "Las actuaciones, peticiones y decisiones que no deban ordenarse, resolverse o adoptarse en la audiencia de formulación de acusación, preparatoria o del juicio oral, se adelantarán, resolverán o decidirán en audiencia preliminar, ante el juez de control de garantías", pareciera que el legislador constitucional, y luego el legal, hubieran asignado el conocimiento de cualquier tema relacionado con el restablecimiento del derecho al juez de conocimiento y no al de garantías, no sólo porque la asignación aparece en forma expresa en las preceptivas indicadas -amén de que ella tiene, reitérese, carácter constitucional- sino porque los textos en cuestión no distinguen si lo perseguido con la medida es el restablecimiento del derecho con carácter provisional o definitivo.

La problemática adquiere mayor complejidad cuando se ausculta el origen de la reforma del Acto Legislativo 03 (2002) frente a este punto en concreto del artículo 250 de la Constitución Política. En efecto, en la exposición de motivos del proyecto de reforma encaminado a preparar el terreno constitucional para la implementación del sistema penal acusatorio en el país, se optó por el hecho de que fuera la Fiscalía quien haga efectivo el restablecimiento del derecho a través de solicitud que hiciere al juez de control de garantías. Lo anterior conduciría a la conclusión de que todo lo referente al restablecimiento del derecho sería de competencia de los jueces de conocimiento, por cuanto se derrotó la asignación original radicada en los jueces de garantía; sin embargo, estos preceptos (tanto el constitucional como el legal) necesariamente deben armonizarse con el artículo 22 de la Ley 906 (2004), que dice taxativamente que cuando sea procedente la Fiscalía y los jueces 
deberán adoptar las medidas necesarias para el Restablecimiento del derecho, ello teniendo en cuenta que esta norma ostenta carácter de principio rector y, por lo mismo, tiene rango superior y debe servir como fundamento de interpretación para aplicar el código de procedimiento penal.

Por otro lado, la jurisprudencia de la Sala Penal de la Corte Suprema de Justicia ha sido reiterativa en precisar que el restablecimiento del derecho a favor de las víctimas, aún antes de la Ley 906 (2004), es intemporal y en esa medida se puede realizar en cualquier momento de la actuación procesal, porque, como ahora lo señala la norma que viene de transcribirse, es independiente a la declaración de responsabilidad penal; por consiguiente, para que opere plenamente, basta con que esté demostrada la materialidad de la conducta o el tipo objetivo.

De ese modo, es procedente aún si la sentencia es absolutoria o frente a eventos en los cuales prescribe la acción penal ${ }^{3}$ o se presenta alguna otra circunstancia de improseguibilidad de la acción penal, destacándose siempre su carácter intemporal e independiente de la responsabilidad penal, como lo sostuvo la Corte Constitucional en decisión ya de vieja data, Sentencia C-245 del junio 24 (1993), al declarar la exequibilidad del artículo 61 del Decreto 2700 (1991).

En ese mismo sentido se pronunció la misma corporación, encargada de la salvaguarda de la Constitución Política, al declarar la inexequibilidad de la palabra "condenatoria" del artículo 101 de la Ley 906 (2004), que consagra una norma de contenido similar a la que determinó el pronunciamiento similar, al señalar que la cancelación de los títulos y registros obtenidos mediante fraude, además de la sentencia, también se podría realizar en cualquier otra providencia que ponga fin al proceso penal, determinación a la cual arribó con fundamento en premisas ya agotadas en el capítulo anterior.

De lo acotado en precedencia se puede hasta el momento inferir: (i) el principio rector orientado al restablecimiento del derecho es intemporal dentro del proceso penal y no está supeditado a la declaratoria de responsabilidad penal; (ii) "el pleno restablecimiento del derecho" no necesariamente se debe reconocer en la sentencia sino en cualquier momento de la actuación en que aparezca acreditado en que obre, como ahora se señala en el artículo 101 de la ley 96 (2004), un 'convencimiento más allá de toda duda razonable' sobre la materialidad de la conducta o en cuanto al tipo objetivo y (iii) en el decurso procesal se debe procurar por el pronto y efectivo resarcimiento, de modo que, como se señala en la

\footnotetext{
${ }^{3}$ De ese modo en sentencia de la Sala de Casación Penal (2009), rad. 22881, en un asunto regido por la Ley 600 (2000), no obstante declararse la prescripción de las acciones penal y civil, se casó oficiosamente el fallo para adoptar medidas de restablecimiento del derecho en favor de las víctimas, concretamente la cancelación de registros de escrituras públicas sobre bienes inmuebles obtenidos de forma fraudulenta, tras encontrar demostrada la materialidad del punible de fraude procesal. 
Meliza Salcedo Alarcón

sentencia C-060 (2008), "se evite la continuación y/o la consumación de situaciones irregulares, así como la de los perjuicios que ellas injustamente causan” o, lo que es igual, no siempre debe ser pleno, sino que también procede con carácter provisional, en cuyo caso demanda la adopción de medidas inmediatas que no se pueden posponer hasta cuando se profiera alguna determinación con carácter definitivo en el proceso.

Desde tal perspectiva ha de inferirse que las medidas de restablecimiento del derecho pueden ser de naturaleza personal, si recaen sobre las personas, o real, en caso de hacerse efectivas respecto de los bienes afectados con la conducta punible, pero, a su vez, pueden ser provisionales o definitivas dependiendo de su contenido, es decir, si tienen por objeto irradiar un manto de protección frente a un posible daño derivado de la comisión de una conducta punible, cuya índole es cautelar o meramente preventivo, o si apuntan a adoptar medidas definitivas tendientes a retornar las cosas a su estado original o predelictual, evento en el cual se exige un convencimiento más allá de toda duda razonable acerca de la materialidad de la infracción o del tipo objetivo.

Los dos tipos de medidas son necesarias para materializar cabalmente los derechos de las víctimas, no sólo reconocidos en el ámbito constitucional y legal interno, al paso que han sido desarrollados ampliamente por la jurisprudencia en las dos materias, sino, además, por múltiples instrumentos internacionales ratificados por el Estado que propenden por la vigencia de los principios de verdad, justicia y reparación a su favor, consagrados entre otras disposiciones en los artículos 9.5 del Pacto Internacional de Derechos Civiles y Políticos, 10 de la Convención Americana sobre Derechos Humanos, 14 de la Convención contra la Tortura y Otros Tratos o Penas Crueles, Inhumanos o Degradantes, 4 de la Declaración sobre los principios fundamentales de justicia para las víctimas de delitos y del abuso de poder, 19 de la Declaración sobre la protección de todas las personas contra las desapariciones forzadas, 49 a 52 del Convenio de Ginebra para aliviar la suerte que corren los heridos y los enfermos de las fuerzas armadas en campaña (Convenio I), 10 y 11 del Protocolo Adicional a los Convenios de Ginebra del 12 de agosto de 1949 relativo a la Protección de las Víctimas de los Conflictos Armados Internacionales (Protocolo I), 50 a 53 del Convenio de Ginebra para aliviar la suerte que corren los heridos, los enfermos y los náufragos de las fuerzas armadas en el mar (Convenio II), 129 y 130 del Convenio de Ginebra relativo al trato debido a los prisioneros de guerra (Convenio III), título III, sección I y artículos 45, 46, 146, 147 del Convenio de Ginebra relativo a la protección debida a las personas civiles en tiempo de guerra (Convenio IV) y 63 de la Convención Americana sobre Derechos Humanos.

Ahora bien, cuando tales medidas son de carácter provisional, independientemente de si son personales o reales, verbigracia, imposición de medida de aseguramiento sobre las 
personas; suspensión del poder dispositivo sobre bienes (arts. 83 y 85 del C.P.P.); suspensión de personerías jurídicas o cierres temporales de locales o establecimientos abiertos al público (art. 91 ibídem); medidas cautelares sobre bienes (arts. 92 a 101 del ejusdem) y suspensión de registros obtenidos fraudulentamente (art. 101 ib.), la competencia es del juez de control de garantías; empero, si lo que se pretende es el restablecimiento pleno del derecho, conforme lo establece la sentencia C-060 (2008), ya no con carácter provisional o transitorio, análisis que comporta juicios concretos y valorativos en punto de la materialidad de la conducta punible o del denominado tipo objetivo, lo cual puede ocurrir en la sentencia o en una decisión que ponga fin al proceso, la competencia será del juez de conocimiento.

Es necesario precisar que el factor para determinar cuál es el funcionario competente no puede ser el de las etapas en que se promueva la solicitud de restablecimiento del derecho, en sentido de que si lo es en las etapas preliminares o de investigación corresponde al juez de garantías, y si lo es en el juicio, al de conocimiento, no sólo porque el criterio acertado es el de la naturaleza de la medida, sino porque de acuerdo con la Sala, con ello se desconoce que, ni la fase preprocesal es de competencia exclusiva de los jueces de control de garantías, ni tampoco la del juicio oral es privativa de los jueces de conocimiento; así como que la intervención del juez constitucional es episódica y se extiende a todo el proceso.

\section{Decisión de restablecimiento del derecho}

Después de abordar todos los temas atinentes al restablecimiento del derecho, no se podía dejar de lado un aspecto fundamental en la implementación de esta institución jurídica, en las salas de audiencias de los juzgados penales. Pues bien, se había mencionado la INTEMPORALIDAD de la figura, es decir no importa el tiempo en que se eleve la solicitud esta será resuelta, por lo menos será atendida, aun cuando no exista indiciado/imputado/acusado, pues el restablecimiento es independiente de la acción penal que se siga en contra de determinadas personas, bastará, como bien se ha dicho, que esté comprobado más allá de toda duda razonable la ocurrencia de un hecho ilícito y que además, esté comprobado que a causa de éste, se privó de un derecho a las víctimas que lo aleguen, y que de resolverse la vulneración, cesaría.

Hasta este momento, está clara esa intemporalidad. Pero siempre se ha hecho referencia, a cualquier tiempo, dentro del proceso. Surge entonces la pregunta ¿es posible restablecer derechos sin que exista acción penal? La respuesta sin vacilar sería NO. No puede existir restablecimiento del derecho sin acción penal, toda vez que esta es la que determina la competencia de los funcionarios judiciales, y en consecuencia determinará la posibilidad de que las víctimas rueguen justicia. 
Meliza Salcedo Alarcón

Sin embargo, la situación no es pacífica en este tópico, pues en algunos casos (experiencias propias) la Fiscalía accede a restablecer derechos en la misma decisión en la que decretan prescripción de la acción penal, bajo el criterio de que esta es una garantía intemporal con independencia del acaecimiento de la prescripción de la acción penal y, en consecuencia, debe accederse a ello en pro de los derechos de las víctimas.

En alguna oportunidad incluso se ordenó el restablecimiento del derecho a pesar de que la conducta punible de FALSEDAD EN DOCUMENTO PÚBLICO se encontraba exageradamente prescrita, pues los hechos habían tenido ocasión hacía más de hace 53 años y la denuncia fue interpuesta casi 49 años después.

En ese aspecto es importante tener claro que, la aplicación de este mecanismo depende de la posibilidad de ejercitar la acción penal, en tal sentido, es necesario que, en principio, el funcionario judicial adquiera el conocimiento en vigencia de la acción, es decir, cuando no haya operado la prescripción, con el fin de que tenga acción, lo cual es un presupuesto necesario para ejercer la jurisdicción.

Es por ello que se ha considerado que en aquellos casos en los cuales, por vía de ejemplo, se decreta la preclusión o se ordena el archivo de las diligencias se restablece el derecho conculcando, por ejemplo, cancelando títulos apócrifos, evitando así desamparar los derechos de las víctimas de la conducta punible. Ese es precisamente el espíritu de la sentencia C-060 (2008); permitir que se retrotraigan situaciones constitutivas de delito, con independencia del señalamiento concreto de responsabilidad penal, en los casos que se han reseñado de manera ilustrativa.

En los casos anteriormente descritos el Estado inicialmente ejercita la acción penal, y en circunstancias sobrevinientes decide cesar la misma. Sin embargo, en el evento de acreditarse la tipicidad objetiva del delito investigado y en aras de salvaguardar los derechos de los afectados es posible ordenar el restablecimiento del derecho, a pesar del decreto de prescripción o archivo.

Sea importante entonces, decir que, el juez no podrá conocer de ninguna acción cuando esta esté prescrita, y en el código penal, ley 599 (2000), artículos 83 y 86 se estipulan estos términos.

Tres son los aspectos que se comprenden de estos artículos; el primero con relación al término fijado taxativamente que será de un tiempo igual al máximo de la pena. Por otro lado, los límites en los que escila, los cuales no serán menos de cinco años ni más de veinte, y, por último, el del artículo 86, que expresa que este término se interrumpe con la 
resolución de acusación, y que a partir de ahí la prescripción se dará en un término igual al de la mitad del primero señalado.

En ese entendido, de permitirse que, en cualquier momento histórico, pudiera revivirse una causa prescrita, además de desconocer la temporalidad del ejercicio de la acción estatal, implicaría una profunda inseguridad jurídica en las transacciones económicas y jurídicas que realizan los ciudadanos, como quiera que, en cualquier tiempo pudieran retrotraerse las mismas perjudicando los derechos de terceros de buena fe.

Razón por la cual, no se comparte el criterio de esa extrema intemporalidad, advirtiendo que esta solo oscilará entre los interregnos del proceso penal, y no de la historia. De ser así el Estado estaría en la obligación de conocer de las solicitudes de restablecimientos de derechos que interpongan, verbigracia, los descendientes de los dueños, cuyos patrimonios fueron despojados por los españoles. Esto sería realmente absurdo. Retrotraer derechos supuestamente vulnerados hace más de 20,30 o 40 años, no sólo no es posible legalmente, sino peligroso en relación a los derechos de los terceros de buena fe, a quienes también se les ven vulneradas sus garantías. Y peor aún, cómo es posible llegar a considerar que un caso que no puede tener vida jurídica, por estar prescito, pueda el funcionario judicial adquirir competencia para restablecer el derecho, entonces también deberá tenerla para conceder los recursos que de él se desprendan, pues el restablecimiento también comporta los argumentos del debido proceso, por lo tanto, los intervinientes tendrán derechos a interponer sus oposiciones. Pero el funcionario, se repite, no podrá atender a ninguna de estas solicitudes por no tener competencia en ningún aspecto que tenga que ver con un proceso que no haya nacido en el derecho, es decir que fácticamente existió, pero procesalmente no.

Partiendo de lo expuesto se debe decir entonces que, el momento oportuno para decidir acerca de las solicitudes de restablecimiento del derecho, será en cualquier momento en que estas se presenten, siempre y cuando sea dentro de un proceso penal, aun cuando la decisión de poner fin al proceso sea por alguna causal de extinción de la acción penal, que no sea la prescripción, pues preferiblemente será en los casos en que no se prive de la competencia a los funcionarios judiciales.

Pero bien, como rápidamente se había avocado, el restablecimiento del derecho responderá a los presupuestos jurídicos del debido proceso, lo que implica el derecho a controvertir los argumentos de quién lo solicita. Es así como tanto defensa como terceros de buena fe, podrán proponer sus recursos, tanto de reposición, como de apelación. Valga hacer la aclaración que, si se trata de un restablecimiento definitivo, que se decida en una decisión que ponga fin al proceso, solo procederá el recurso de apelación. 
Meliza Salcedo Alarcón

En relación a este tema, la ley procesal muy poco aporta. Pues cuando se habla de los efectos del recurso de alzada, no se hace referencia a la decisión de restablecimiento de derecho, sin embargo, aquí es necesario ofrecer una estructura teórica más expansiva y flexible de la norma, de la que se pueda proporcionar incluso un enfoque de equilibrio con relación al espíritu de las medidas que se tornan necesarias para restablecer derechos. Y esto es, pues proteger los derechos de las víctimas que se han visto afectados por la comisión de una conducta punible, retrotrayendo las cosas al estado anterior.

En el artículo citado se menciona que se concederá el recurso de apelación en el efecto devolutivo cuando se trate de "El auto que resuelve sobre la imposición de una medida cautelar que afecte bienes del imputado o acusado". Entonces, partiendo del supuesto de que, las medidas cautelares son decretadas con el fin de asegurar que cierto derecho, podrá hacerse efectivo en el caso de un litigio donde se reconozca la existencia y legitimidad de tal. Y el Restablecimiento busca otorgar medidas que conlleven al goce, ya sea temporal o definitivo, de los derechos que a causa de un ilícito estaban siendo vulnerados. Se podría hacer extensiva la idea de que, si para las medidas cautelares se concede el recurso de apelación en el efecto devolutivo, igual deberá concederse en las decisiones que se emitan en torno al restablecimiento de derechos, pues ambas son medidas con espíritu garantista de los derechos de las víctimas.

\section{CONCLUSIONES}

- El Restablecimiento del derecho no es lo mismo que indemnizar o resarcir perjuicios, pues este se entiende en un contexto más amplio el cual garantiza el goce del derecho afectado por la comisión del delito, cuando el juez adopta medidas necesarias que impliquen, en lo posible, volver a las situaciones y condiciones preexistentes a la comisión del hecho.

- En este sistema procesal penal, se encuentran establecidos ciertos derechos susceptibles de restablecimiento del derecho, los cuales han sido desarrollados jurisprudencialmente, como es el caso del artículo 101 del Código de Procedimiento Penal (ley 906,2004), el cual es desarrollado ampliamente por la sentencia C- 060 (2008), consistente en cancelación y suspensión de títulos obtenidos fraudulentamente. Sin embargo estas no son las únicas posibilidades de restablecer derechos, pues en los casos que no están plasmados en la ley, se probará la creatividad (de los jueces al decidir y por supuesto de la fiscalía y las víctimas al momento de solicitar), para crear las medidas necesarias para restablecer los derechos en esos casos, pues no todos los casos están textualmente en la ley, y a diario se encuentra en los juzgados solicitudes de restablecimientos de derechos no fundamentados en ningún artículo de la ley, simplemente se ingenian la manera de 
proteger los derechos de las víctimas de cualquier forma, lo cual es totalmente válido dentro de un Estado garantista de proteger los derechos fundamentales de sus asociados.

- El restablecimiento del derecho podrá hacerse de manera de transitoria y de manera definitiva, eso dependerá de la etapa procesal en que se ubique la solicitud, lo cual va de la mano con la competencia de los jueces. De acuerdo con esto, si se solicita en cualquier momento de la indagación, antes de la formulación de acusación, la competencia será de los jueces de control de garantías y será una más de las audiencias preliminares que surgen en el proceso penal, será nominada porque, por su naturaleza, siempre se llamará -audiencia de solicitud de restablecimiento del derecho-. Sin embargo, si se solicita, ya estando asignado el proceso a un juzgado de conocimiento. La competencia será de éste, solo cuando le corresponda dictar una decisión que ponga fin al proceso.

- Cuando las medidas necesarias para restablecer derechos son de carácter provisional, independientemente de si son personales o reales, la competencia es del juez de control de garantías; empero, si lo que se pretende es el restablecimiento pleno del derecho, ya no con carácter provisional o transitorio, y que comporte análisis, juicios concretos y valorativos en punto de la materialidad de la conducta punible o del denominado tipo objetivo (lo cual puede ocurrir en la sentencia o en una decisión que ponga fin al proceso) la competencia será del juez de conocimiento.

- La ley y la jurisprudencia ha sido clara en determinar quiénes serán los legitimados para invocar el restablecimiento del derecho, y según lo dicho serán los fiscales por estricta orden de la ley, y las víctimas por desarrollo jurisprudencial. Nada se dice a cerca de la posibilidad de que los jueces puedan solicitarla de oficio. Eso acabaría con la imparcialidad que debe tener el juzgador con relación a los derechos de las víctimas y de los terceros con interés dentro de los procesos en los cuales, a causa de un restablecimiento se vean afectados sus derechos patrimoniales, los cuales fueron obtenidos de buena fe.

Es por eso no se encuentra la posibilidad que de oficio el juez, independientemente del sentido de su decisión, sea capaz de afrontar un análisis que de entrada está siendo propuesto por él mismo y que requiere de la objetividad en su estudio para poder garantizar la imparcialidad en todos los ámbitos. 
- La jurisprudencia de la Sala Penal de la Corte Suprema de Justicia (2009) ha sido reiterativa en precisar que el restablecimiento del derecho a favor de las víctimas, aún antes de la Ley 906 (2004, es intemporal y en esa medida se puede realizar en cualquier momento de la actuación procesal, porque es independiente a la declaración de responsabilidad penal; por consiguiente, para que opere plenamente, basta con que esté demostrada la materialidad de la conducta o el tipo objetivo. Sin embargo, no se puede entender esa intemporalidad en sentido extremo, es decir esta solo ooscilará entre los interregnos del proceso penal, y no de la historia, como erróneamente se ha llegado a creer pues restablecer derechos supuestamente vulnerados hace más de 20 años, no sólo no es posible legalmente, sino peligroso en relación a los derechos de los terceros de buena fe, a quienes también se les ven vulneradas sus garantías.

- El restablecimiento del derecho responderá a los presupuestos jurídicos del debido proceso, lo que implica el derecho a controvertir los argumentos de quién lo solicita. Es así como tanto defensa como terceros de buena fe, podrán proponer sus recursos, tanto de reposición, como de apelación. Valga hacer la aclaración que, si se trata de un restablecimiento definitivo, que se decida en una decisión que ponga fin al proceso, solo procederá el recurso de apelación.

En relación con este tema, la ley procesal muy poco aporta. Pues cuando se habla de los efectos del recurso de alzada, no se hace referencia a la decisión de restablecimiento de Derecho.

- Se podría hacer extensiva la idea de que, si para las medidas cautelares se concede el recurso de apelación en el efecto devolutivo, de acuerdo al artículo 177 inciso 2 numeral 2, igual deberá concederse en las decisiones que se emitan en torno al restablecimiento de derechos, pues ambas son medidas con espíritu garantista de los derechos de las víctimas.

\section{REFERENCIAS BIBLIOGRAFICAS}

Barbosa, G. (2007). Aspectos concretos del Restablecimiento del derecho en la ley 906 de 2004. Bogotá, D. C. - Colombia. Congreso Colombiano de Derecho Procesal- Universidad Libre.

Bernal, J. \& Montealegre E. (2004). El proceso penal. Fundamentos constitucionales del nuevo sistema acusatorio. $5^{\text {a }}$ edición. Bogotá, D. C. - Colombia: Universidad Externado de Colombia. 
Gaviria, V. (2002). La acción civil en el proceso penal colombiano. 3ra. Edición Bogotá, D. C. - Colombia. Universidad Externado de Colombia.

Martínez, G. (2006). Procedimiento penal colombiano. Sistema acusatorio. Bogotá, D. C. - Colombia. Editorial Temis S. A.

Tamayo, J. (1993). La indemnización de perjuicios en el proceso penal. Medellín. Dike.

Corte Constitucional de Colombia. Sentencia C- 060 de 2008. [MP Nilson Pinilla Pinilla del 30 de enero de 2008]

Corte Constitucional de Colombia. Sentencia C- 209 de 2007. [MP Manuel José Cepeda Espinosa 21 de marzo de 2007]

Corte Constitucional de Colombia. Sentencia C- 893 de 2013. [MP Jorge Ignacio Pretelt Chaljub del 20 de noviembre de 2013]

Corte Constitucional de Colombia. Sentencia C-245 de 1993 [MP Fabio Morón Díaz del 24 de junio de 1993]

Corte Suprema de Justicia de Colombia. Sala de Casación Penal. Sentencia 40246 de 2012 [MP Jorge Luis Barceló Camacho del 28 de noviembre de 2012]

Corte Suprema de Justicia de Colombia. Sala de Casación Penal Sentencia 22881 de 2009 [MP Alfredo Gómez Quintero del 10 de junio de 2009]

Corte Constitucional de Colombia. Sentencia SU 182 de 1998 [MP Carlos Gaviria Díaz, José Gregorio Hernández Galindo del 6 de mayo de 1998]

Congreso de la República de Colombia. (2004, 1 de septiembre). Ley 906 de 2004. Código de Procedimiento Penal Colombiano. Diario oficial no 45.658.

Presidencia de la República de Colombia. (1991, 30 de noviembre). Decreto 2700 de 1991. Nuevo Código de Procedimiento Penal Colombiano. Diario oficial nº 40.190.

Congreso de la República de Colombia. (2002, 20 de septiembre). Acto legislativo 03 de 2002. Por el cual se reforma la Constitución Nacional. Diario oficial n ${ }^{\circ} 45.040$. 
Meliza Salcedo Alarcón

Congreso de la República de Colombia. (2000, 24 de julio). Ley 600 de 2000. Código de Procedimiento Penal. Diario oficial no 44.097.

Congreso de la República de Colombia. (2000, 24 de julio). Ley 599 de 2000. Código Penal. Diario oficial $n^{\circ} 44.097$. 